\title{
CONSTRUCTIVISM, TECHNOLOGY, AND THE FUTURE OF CLASSROOM LEARNING
}

\author{
ERIK F. STROMMEN \\ Children's Television Workshop \\ BRUCE LINCOLN \\ Bank Street College of Education
}

In order to develop our view of the revolution that technology is creating in education, it is helpful to briefly consider how technology has revolutionized American culture, and how it has left our educators rushing to catch up. In barely 20 years, electronic technology has dramatically penetrated into every area of society, and every aspect of our social and cultural lives. Television was the initiator. Broadcast images inaugurated a new, immediate, and powerful way of experiencing ideas and events. Television rediscovered and recast the world as a direct experience, and liberated it from the confines of text and static illustrations. It became possible for events a world away to appear in our homes, with all their intensity and vividness intact. Computers made it possible for vast amounts of information, from airline reservations to the contents of encyclopedias, to be made instantly available and modified with a keystroke. Writing became a matter of screens and printers, and text became permanently flexible, always ready to be instantly changed. The very nature of work changed, with an increasing demand for workers who could master the new technologies and use them to conduct business that formerly did not require computers at all.

Most significant, however, are the changes wrought in our children by the technological revolution. Children have grown up with remote controls, and spend more time watching television and video tapes than reading. Toys are now filled with buttons and blinking lights. They talk and listen, and interact with children, responding to them in ways the stuffed animals and hobby horses of the past did not. Pinball arcades, the quintessential teenage amusement, have become blooming, buzzing multimedia centers where TV images dance at the command of the user. Computer-based information kiosks have become a common feature of malls, museums, and other public places. Atari and Nintendo ultimately brought electronic entertainment right into the living room, making interactive technology as common in the home as television had been in the past. Our children have been raised in a world of instant access to knowledge, a world where vivid images embody and supplement information formerly presented solely through text. They are used to an environment where they control information flow and access, 
whether through a video game controller, remote control, mouse, or touchtone phone.

Although the schools are embedded in our culture and reflect its values, the technological changes that have swept through society at large have left the educational system largely unchanged. In the course of 20 years, a dramatic rift has opened between the process of teaching and learning in the schools and the ways of obtaining knowledge in society at large, a rift made obvious by the fact that the process of teaching has not changed substantially, even in the past 100 years (David, 1990; Kolderie, 1990).Teachers' colleges and education departments around the country have not seen any wholesale revisions in their curriculum, and graduates of these institutions are much more like their predecessors who graduated decades earlier than they are like today's children. The result is an estrangement of the schools from society, and from the children who live in it.

This estrangement has had pronounced negative effects. It has caught our children in an awkward bind as they move toward the future, but the institutions responsible for educating them are locked in the past. In the classroom, knowledge is presented to them in a linear, didactic manner that differs dramatically from children's previous experience outside the school. In contrast with the vivid images and self-directed flow of the interactive home and society, school strikes them as rigid, uninteresting, and ultimately alienating. In our view, the resolution of this divergence between our students and our educational practice lies in drastic educational reform, reform that will bring the classroom into line with society. The immediate task for American education is to embrace the future and empower our children to learn with the cultural tools they have already been given (Soloway, 1991).

\section{A FRAMEWORK FOR EDUCATIONAL REFORM: CONSTRUCTIVISM}

How do we educate the "new child," raised in a world of instant information, where interactive technologies have led them to believe they can act on the world with the press of a button? Not by simply thinking up clever ways to use computers in traditional courses. Such exercises relegate technology to a secondary, supplemental role that fails to capitalize on its most potent strengths. What is needed is a guiding philosophy that suggests principled changes in the curriculum, and effective uses of technology as part of these changes. We think that this philosophy must be constructivism, a theory of cognitive growth and learning that has gained many adherents in recent years (c.f. Forman \& Pufall, 1988; Newman, Griffin, and Cole, 1989; Piaget, 1973; Resnick, 1989; Vygotsky, 1978). 
A brief overview of constructivist ideas reveals their utility. One foundational premise is that children actively construct their knowledge. Rather than simply absorbing ideas spoken at them by teachers, or somehow internalizing them through endless, repeated rote practice, constructivism posits that children actually invent their ideas. They assimilate new information to simple, pre-existing notions, and modify their understanding in light of new data. In the process, their ideas gain in complexity and power, and with appropriate support children develop critical insight into how they think and what they know about the world as their understanding increases in depth and detail. Constructivism emphasizes the careful study of the processes by which children create and develop their ideas. Its educational applications lie in creating curricula that match (but also challenge) children's understanding, fostering further growth and development of the mind.

Two specific features of constructivist philosophy hold particular promise. The first is the notion, borrowed from research in child development, that play and experimentation are valuable forms of learning (c.f. Daiute, 1989; Garvey, 1977; Herron \& Sutton-Smith, 1971). Play involves the consideration of novel combinations of ideas, and the hypothetical outcomes of imagined situations and events. It is a form of mental exploration in which children create, reflect on, and work out their understanding.

Actual experimentation, the manipulation and testing of ideas in reality, provides children with direct, concrete feedback about the accuracy of their ideas as they work them out. Both play and exploration are self-structured and self-motivated processes of learning. Both also encourage children to reflect on their ideas in ways generally not promoted by current school curricula.

Play and experimentation are powerful forces in the development of the individual mind, but constructivism has led to the additional discovery that powerful gains are made when children work together, as well. A growing body of research on collaborative or cooperative learning has demonstrated the benefits of children working with other children in collective learning efforts (Johnson, Maruyama, Johnson,Nelson, \& Skon, 1981; Rysavy \& Sales, 1991). When children collaborate, they share the process of constructing their ideas, instead of simply laboring individually. The advantages of this collective effort are that children are able to reflect on and elaborate not just their own ideas, but those of their peers as well. Children come to view their peers not as competitors but as resources. Mutual tutoring, a sense of shared progress and shared goals, and a feeling of teamwork are the natural outcomes of cooperative problem-solving, and these processes have been shown to produce substantial advances in learning. The focus of constructivism, then, is the child as a self- governed creator of knowledge. Educational practices that follow from this focus are 
designed to facilitate children's learning by nurturing their own, active cognitive abilities. To accomplish this end, a supportive environment, one in which they can create their own ideas, both individually and collaboratively, must be provided. We have chosen the term "child-driven learning environment" (CDLE) to describe this new model of education. Two key features of CDLEs are the changed relationship between teacher and student, and the provision of a resource-rich, activity-based curriculum for learning. In traditional classrooms, the teacher's role is that of the sole giver of knowledge and the student's role is that of the passive recipient. A CDLE does away with this hierarchic structure and operates according to an egalitarian, cooperative structure where the ideas and interests of the children drive the learning process. The teacher serves as a guide, rather than the source, of knowledge. The performance required for this new role is far more complex than traditional classroom teaching (Ringstaff, Sandholtz, and Dwyer, 1991). The teacher engages the children by helping to organize and assist them as they take the initiative in their own self-directed explorations, instead of directing their learning autocratically. Flexibility is the most important feature of the new role the teacher will have to play in such an environment. In a CDLE, sometimes teachers will find that their role tends towards the old model of teacher as giver of knowledge because at that particular time, students require guidance and training in a particular task or content area. More often, the teacher will be moving around the classroom, among groups of children, assisting individual children or the group as a whole.

\section{TECHNOLOGY AND CHILD-DRIVEN LEARNING}

Technology takes a special place in the CDLE as a powerful tool for children's learning by doing. Children's traditional classroom tools - pencils, notebooks, and texts - are still vital. But for children to assemble and modify their ideas, access and study information, they are inadequate. Computers, video, and other technologies engage children with the immediacy they are used to in their everyday lives, and bends it to a new pedagogical purpose. Really, it is not what equipment is used in the classroom, but how that equipment is used that will make the difference. We think that technology must be thought of as an integral component of the curriculum, a chameleon-like tool that can be used with almost any content. Computers can be used as writing tools, spreadsheets, and mathematical problemsolvers.

Technology makes possible the instant exchange of information between classrooms as well as individual students; it allows instant access to databases and online information services, and provides multimedia technical resources such as interactive audio and video. Technology also 
allows for the repurposing of pre-existing educational materials across media formats: print, static illustrations, still and digital photographs, digital audio, still and motion video, still and motion film, animations, computer graphics, and hypermedia can all be accessed and combined in novel ways.

While some have expressed fear that traditional sources of information may be ignored or underutilized, our experience is that the opposite is actually true. Books, magazines, periodicals, newspapers, journals and other socalled "traditional" print materials are integral information sources providing at-hand information that serves as a crucial complement to computer-based information sources. In actual practice, there is a cross fertilization of information sources across media formats as children incorporate information gleaned from readings, as well as other media, into their projects. In urban settings, where large and diverse sets of archival information, both in texts and images, are available technology has a particularly powerful role to play. Historical and scientific information formerly limited to a single extant photo, or available only in a single copy of a book, can achieve greater exposure because it can be reclaimed or "repurposed," as a computer file that can be copied and distributed easily and effectively.

\section{AN EXAMPLE}

How would the "new" CDLE classroom look? The contrast between a CDLE and the conventional classroom are best illustrated by example. Consider two hypothetical junior high school classrooms teaching computer programming. In a traditional classroom, the teacher lectures to the students each day about a particular procedure, while the children sit at desks and listen or take notes. Assigned readings are the dominant medium. The class is held in the computer lab, and children take turns working individually at the computers on weekly or bi-weekly programming assignments. Competence in programming is assessed via written tests, and through evaluation of the weekly programs written by the children to prove their competence with the assigned programming procedure.

The same curricula covered in a CDLE looks very different. The Visual Language Laboratory (VLL), developed and implemented by the second author of this paper at New York's Bank Street College, is a course in programming using the MacIntosh Hypercard environment that is meant to embody the CDLE model. The students are so-called "at-risk" Black and Latino junior high school students. Rather than lead the children through a teacher-directed, step-by- step introduction to Hypercard procedures, the class is organized around student-originated projects that utilize the Hypercard system as an expressive medium. The focus on single complex 
projects, rather than on a series of smaller exercises embodying different Hypercard procedures, deserves comment. First, requiring the children to conceive of and execute an entire program by the end of the course presents them with a rich, open-ended, self-directed task in which they can explore the various procedures and how they interact, rather than simply learn them in isolation from one another, in a rote fashion. Second, the emphasis on an end-product grounds children in a meaningful task, in which an initial idea is seen to undergo changes as it is turned into an actual product.

The class is organized as a four-step process. The first step is exploration. During this period, the children are introduced to the MacIntosh system, and allowed to explore various pre-existing Hypercard programs, so they become familiar with the capabilities of the programming language. The second step is conceptualization, during which the children devise a "storyboard" or "flowchart" of their own proposed program. The third step is production, where the children assemble the materials needed for their project and make a first attempt at developing the actual program. This step often involves children spending time outside the classroom, either composing the text to be included in their program, or assembling the images and sound content that will be used. This initial program, and all previous versions to date, are submitted to the educator for evaluation at this point. This phase is analogous to having children submit a first draft of a paper for review by the teacher in a regular classroom. The final phase is post-production. During this period, students modify the design and scripting of their projects in response to feedback from the educator and other students, in order to address problems encountered in the design process. Finishing touches such as full sound tracks and special effects are added at the end of this period. The final product, and all previous versions, are submitted to the teacher. The class culminates in a public presentation of the completed projects, to which parents, other educators, and students, are invited.

Several specific outcomes of this project, now in its second year, are noteworthy. The first is the nature of the student projects. In traditional programming classes, students are permitted to produce only a narrow set of types of programs as their projects. In the VLL, where students can select their own project content, programs such as animated street scenes, branching stories based on rap lyrics, and interactive picture books are common. An examination of the structure of these programs reveals that they employ the Hypercard procedures that were the focus of the curriculum in a complex and intelligent manner. Second, although the classroom contains one computer per student, making it possible for all children to work individually, active collaboration among children was the rule. In fact, the children seldom work alone, even when they are each using their own computer. Without prompting, the children's projects spontaneously became group efforts. It is common to observe one child tutoring another in a new 
procedure, or two children making recommendations for improvement in each others' project designs while they are working on them.

Third, the role of the teacher is significantly more complex. He has many roles: project manager, tutor, and lecturer. The teacher is a member of the team, and not the focus of the classroom. He provides technical assistance and creative consultation, rather than directs the children in the creation of narrowly defined tasks. Students generally turn to the teacher for assistance when needed, but otherwise his role is more that of a colleague than of a superior. In actuality, the teacher also becomes a student as the children discover new procedures and instruct the teacher in their use. On several occasions, the teacher was surprised when students demonstrated different new uses of the Hypercard system that he had not seen before! Finally, the children spend much time performing other pedagogically significant activity that is not directly computer related. The children practice library research skills, for example, as they search for images and text to include in their programs. They also practice writing, as they compose their own poetry and prose for inclusion as well. Such writing (mainly inspired by rap!) is a major feature of many of the children's projects.

\section{GETTING THERE FROM HERE}

It should be apparent from the previous discussion that while crucial, we believe that technology in and of itself cannot be the focus of the changes that are needed in American education. As noted by Riel (1990), "...new tools alone do not create educational change. The power is not in the tool but in the community that can be brought together and the collective vision that they share for redefining classroom learning (p.35)." We believe that what is needed is a wholesale revision of educational practice that focuses on children's own competencies, the ones they bring with them upon entering school. Technology is vital to this effort because it is a medium with its own, new forms of discourse that our children already grasp. They can turn their understanding of this new medium to their advantage when so instructed. The key to success lies in finding the appropriate points for integrating technology into a new pedagogical practice, so that it supports the deeper, more reflective self-directed activity children must use if they are to be competent adults in the future.

As we see it, there are two distinct obstacles to implementing the dramatic changes our educational system needs. The first is the systemic lack of awareness of the appropriate uses of technology in our schools today. There is a long historical precedent for this lack of knowledge (Collins, 1990). The classroom has traditionally been the last institutional space in our society to be penetrated by any new technology, be it calculators, VCRs, or computers 
(Soloway, 1991). This is partially the result of limited budgets, and partially the result of limited experience on the part of educators and administrators it is difficult to conceive of pedagogically sound ways to apply a technology when you are not familiar with it. Similarly, our teacher's colleges and institutions of higher education have not made it a priority to reflect on the pedagogical potential of technology when teachers are trained. The normative tendency in education has been, unfortunately, to treat computers and other electronic media as add- ons. The result of this practice is that computers become little more than "electronic workbooks," bearing an awkward and peripheral relationship to an otherwise unchanged curriculum.

In order to incorporate technology more fully into the classroom, several changes are needed. Teachers must be provided with the time and support to explore technology on their own. Administrators must provide the time ands pace for teachers, who now suffer from larger classes and more responsibility than ever, to take a break from teaching to start learning. Teachers must be treated like the professionals they are. Teacher creativity is a powerful force for positive educational change, but it can thrive only if it is unleashed and supported by strong institutional commitments.

The second obstacle to reconceptualizing educational practice is the absence of new forms of assessment with which to measure the effectiveness of the new forms of classroom learning being developed. As education becomes a collective effort between children, and educational methods come to emphasize the actual process of children's construction of new ideas, new techniques for measuring performance will be necessary. This is an area of active research (see Collins, Hawkins, and Frederiksen, 1991; Frederiksen and Collins, 1990, and Wolf, Bixby, Glenn III, and Gardner, 1991 for developments in this area). Based on our experiences with the Visual Language Laboratory, two new types of assessment, both of which capture the development of ideas, seem especially promising. The first is assessment of children's learning processes as they are occurring. Videotaped records of student interactions as they work, for example, reveals their grasp of the course material, as well as their ability to communicate it to others. Similarly, video records of individual children's debugging of their own programs gives evidence of their level of understanding of the programming procedures they are using. The types of errors children perform, and how they correct them, are a rich source of information about children's understanding.

A second new form of assessment we have found promising is the evaluation of a portfolio that shows the evolution of a child's work as it is created, rather than of a single completed work or a set of isolated exercises. In the VLL, children provide the educator with complete records of their progress in creating their programs. These records are both printed and on disk. These different versions of the children's projects, collected over time, 
allow the educator to follow the development of subsequent versions of the program and evaluate the student's progress in learning and applying different Hypercard procedures. Such records document the student's progress in learning, and allow the educator to identify areas where individual students may require tutoring in specific procedures. Both of these methods are more demanding on the teacher than traditional forms of evaluation. However, they are worth the effort because they capture qualitatively different, and much more detailed, information about children's actual competence than their traditional counterparts.

\section{SUMMARY}

Technology has effectively revolutionized American society. An unexpected byproduct of this revolution has been the emergence of a generation of children weaned on multidimensional, interactive media sources, a generation whose understanding and expectations of the world differ profoundly from that of the generations preceding them. If we are to give these children the education necessary to succeed in our technologically intense, global future a new form of educational practice, one that builds on children's native learning abilities and technological competence, must replace our existing methods. The theoretical foundation for such changes exists, and the time to implement them is now. We have allowed our schools to remain in the past, while our children have been born in the future. The result is a mismatch of learner and educator. But it is not the children who are mismatched to the schools; the schools are mismatched to the children. Only by revising educational practice in light of how our culture has changed can we close this gap, and reunite our schools with our children and the rest of our society.

\section{REFERENCES}

Collins, A. (1990). The role of computer technology in restructuring schools. In K. Sheingold \& M.S. Tucker (Eds.), Restructuring for learning with technology, (pp.29-46). NY: Center for Technology in Education, Bank Street College and the National Center on Education and the Economy.

Collins, A., Hawkins, J., \& Frederiksen, J. R. (1991). Three different views of students: The role of technology in assessing student performance (Technical Report No. 12). New York, NY: Center for Technology in Education, Bank Street College of Education.

Daiute, C. (1989). Play as thought: thinking strategies of young writers. Harvard Educational Review, 59(1), 1-23. 
David, J.L. (1990). Restructuring and technology: Partners in change. In K. Sheingold \& M.S. Tucker (Eds.), Restructuring for learning with technology, (pp.75-89). New York: Center for Technology in Education, Bank Street College and the National Center on Education and the Economy.

Dede, C. (1990). Imaging technology's role in structuring for learning. In K. Sheingold \& M.S. Tucker (Eds.), Restructuring for learning with technology, (pp.49-72). New York: Center for Technology in Education, BankStreet College and the National Center on Education and the Economy.

Forman, G., \& Pufall, P. B. (Eds.). (1988). Constructivism in the computer age. Hillsdale, NJ: Lawrence Erlbaum Associates, Publishers.

Frederiksen, J. R., \& Collins, A. (1990). A systems approach to educational testing (Technical Report No. 2). New York: Center for Technology in Education, Bank Street College of Education.

Garvey, C. (1977). Play. Cambridge, MA: Harvard University Press.

Herron, R. E., \& Sutton-Smith, B. (Eds.). (1971). Child's Play. New York: Wiley.

Johnson, D. W., Maruyama, G., Johnson, R., Nelson, D., \& Skon, L. (1981).Effects of cooperative, competitive, and individualistic goal structures on achievement: A metaanalysis. Psychological Bulletin, 89, 47-62.

Kolderie, T. (1990). How structural change can speed the introduction of technology. In K. Sheingold \& M.S. Tucker (Eds.), Restructuring for learning with technology, (pp.91-103). New York: Center for Technology in Education, Bank Street College, and the National Center on Education and the Economy.

Newman, D., Griffin, P., \& Cole, M. (1989). The construction zone: Working for cognitive change in school. New York: Cambridge University Press.

Piaget, J. (1973). To understand is to invent. New York: Grossman.

Resnick, L. B. (1989). Developing mathematical knowledge. American Psychologist, 44, 162-169.

Riel, M. (1990, January/February). Building a new foundation for global communities. The Writing Notebook, pp.35- 37.

Ringstaff, C., Sandholtz, J. H., \& Dwyer, D. (1991, April). Trading places: When teachers utilize student expertise in technology-intensive classrooms. Paper presented at the annual meeting of the American Educational Research Association, Chicago.

Rysavy, S. D. M., \& Sales, G. C. (1991). Cooperative learning in computer-based instruction. Educational Technology Research and Development, 39, 70-79.

Soloway, E. (1991). How the Nintendo generation learns. Communications of the ACM, 34(9), 23-26, 95. 
Vygotsky, L. S. (1978). Mind in society: The development of higher psychological processes (M. Cole, V. John-Steiner, S. Scribner, \& E. Souberman, Eds.). Cambridge, MA: Harvard University Press.

Wolf, D., Bixby, J., Glenn III, J., \& Gardner, H. (1991). To use their minds well: Investigating new forms of student assessment. Review of Research in Education, 17, 3174. 